\title{
FREE RIDING AND COLLECTIVE ACTION: AN EXPERIMENT IN PUBLIC MICROECONOMICS*
}

\section{FRIEDRICH SCHNEIDER AND WERNER W. POMMEREHNE}

The well-known free-rider hypothesis is examined experimentally to see (i) whether individuals behave systematically as free riders when systematic incentives to do so are created, and (ii) the extent to which free riding actually occurs. Though the experiment's participants behaved in accordance with the hypothesis, the quantitative extent to which such behavior occurred was rather modest. From this it may be concluded that the free-rider hypothesis as presently stated indicates an incompleteness in standard public microeconomics rather than providing a description of the real world.

The free-rider hypothesis is one of the "evergreens" of economic literature. In 1740 Hume [Part II, Book 2] was already describing the inclination of individuals to profit from collective activities without making a fair contribution of their own; and today there is almost nothing written on public goods that does not contain at least a reference to this problem. This behavior is said to arise when prohibitive costs make exclusion of individuals from the consumption of a good impossible. People will then act strategically by (depending on the mode of financing) stating a willingness-to-pay for the public good that is either higher or lower than their true willingness-to-pay.

Free riding has achieved even greater importance in the literature in recent years because research has shown that incentives for nondisclosure are not restricted to public goods. As Satterthwaite [1975] has shown using a basic impossibility theorem, there may be incentives not to state true preferences even in an economy without externalities and with only private goods. The nature of the incentives involved does not depend solely on whether a good is public or private, but on the size of the group involved as well: As the number grows, it becomes increasingly less attractive for the individual to conceal his/her true preferences when private goods are concerned, and increasingly more attractive with public goods.

Presumably this impossibility theorem can be evaded-as in the case of the Arrow impossibility theorem-by restricting the admissible individual preferences. ${ }^{1}$ Approaching the matter from another angle,

* We are grateful to students at the University of Zurich for their (unwitting) help in the experiment, to Bruno S. Frey and Peter Zweifel for helpful comments on an earlier version of this paper, to two anonymous referees, and to the editorial board of this Journal for most valuable suggestions. We also thank the participants of two seminars held at the universities of Illinois at Urbana-Champaign and Carleton (Ottawa) for stimulating discussions, and Sandra Stuber for editing the paper for English.

1. See Arrow [1977] 
decentralized mechanisms for motivating people to reveal their true willingness-to-pay can be developed theoretically. Such mechanisms would depend on a system of reward and punishment, both functions of the stated willingness-to-pay. ${ }^{2}$ How effective these incentivecompatible mechanisms would be, however, is debatable. Smith [1977, $1979 a, 1979 b, 1980$ ] has concluded from the results of his experiments that there are indeed decentralized mechanisms that can facilitate efficient collective-good decisions. But his experiments were done with small groups only, and under the condition of unanimity of the individual decision-makers before the final group decision was made. Applying his procedure to a typical public-good situation (many people, no condition of unanimity, prohibitive transaction costs within the group) could lead to quite different results. ${ }^{3}$ Other economists have shown that the individuals themselves may be able to manipulate the demand-revealing mechanisms; and, further, that incentives may arise for forming coalitions and stating biased group preferences. ${ }^{4}$

In this paper the free-rider phenomenon is approached from a different perspective. The argument here presented is that the present free-rider hypothesis may reflect incompleteness of standard economic theory rather than a description of the real world. Indeed, as we shall briefly discuss in Part I, there may be some forces in the individual's decision-making process for public goods that run counter to her/his inclination to take a free-rider position. The extent to which free riding will actually occur in reality is thus a matter for empirical research. To try to discover whether this might be the case, we conducted an experiment structured to allow us to measure the extent to which people will behave as a free rider in a particular situation. This is discussed in Part II, and the results evaluated in Part III. They confirm those of past studies and previous experiments done by others which indicate that free riding cannot always be presumed to occur. They show that there is no voluntary revelation of true full willingness-to-pay, but the disclosure of demand is much greater than might have been predicted on the basis of the literature, which tends to stress the strength of the free-rider incentive.

2. For these mechanisms, see Clarke [1971], Tideman [1972], Groves [1973], Tideman and Tullock [1976], and Groves and Ledyard [1977]. Surveys of what have come to be numerous contributions on the subject are given in Clarke [1978] and Green and Laffont [1978].

3. Also see the carefully done experiment by Scherr and Babb [1975], who examine two demand-revealing mechanisms of the same incentive structure for whether the willingnesses-to-pay whose declaration they lead to are identical. The null hypothesis; i.e., that the stated willingnesses-to-pay are identical, is rejected.

4. See, e.g., Roberts [1976], Green and Laffont [1978], and various contributions in a supplementary volume of Public Choice, XXIX (April 1977). A critical evaluation of the most important incentive-compatible mechanisms is given in Mueller [1979]. 


\section{Pitfalls in the Traditional View of Free Riding}

The free-rider hypothesis as stated by Samuelson [1954], Musgrave [1959, Ch. 1], and others, and repeated in public economics textbooks, says that public goods will inevitably be undersupplied as compared with the Pareto-optimal amount. A stronger version of this hypothesis, which seems to be supported for instance by Olson [1965, pp. 48ff.], goes even farther and asserts that some public goods will not be provided at all.

This dominating importance attributed to the free rider, however, has not gone unquestioned. Stigler [1974], for instance, has pointed out that the usual assumptions do not suffice to explain why firms and individuals voluntarily join an organization that produces a private and a public good (e.g., a trade association providing a public intermediate good in addition to a private good). Under the assumption that a firm or individual will still be able to enjoy the public good without contributing to the organization, the rational decision-maker should join a rival organization (producing only the private good, and thus be able to offer it at a lower price) and try to free ride on the public good provided by the first organization. ${ }^{5}$ One possible explanation for the fact that such free riding does not always occur, Stigler argues, is that the public good may have a number of distinct characteristics, and in order for a firm or individual to ensure that the public intermediate good actually provided has the particular mixture of characteristics that it wishes, it must take part in the collective action needed to provide the public good.

McMillan [1979a] has recently provided another possible explanation. He takes the case of repetitive decisions made by firms on public intermediate goods. In such a dynamic context there may be incentives not to behave as a free rider (incentives that do not exist in a static framework) because there is a cost attached to free riding. The effect of a firm's decision will be observed by the others and will influence their behavior in the future. If it is seen that the supply of public goods is falling due to free riding of a firm, and if all other firms react to this by reducing their own contributions to the provision of the public good, then the benefit derived from free riding will soon be outweighed by the disadvantage of being provided with an indi-

5. It is evident that this case is not covered by Olson's [1965] "by-product" theory which hypothesizes that an organization will produce a public and a private good joined together in some way and where a person (or firm) can be excluded from enjoying the private good if he/she does not contribute to the provision of the public good. It is obvious that such an institutional arrangement can keep a firm or individual from taking a strong free-rider position. 
vidually suboptimal amount of the public good in the future (provided that future benefits are not discounted too heavily).

In the case where the public good is a consumption good, however, we can expect free riding to occur to a greater extent. But even here there may be incentives not to take a strong free-rider position. As proposed by McMillan [1979b], each individual may have an a priori idea (represented by a probability distribution) as to the likely amount of the public good that will be provided as the aggregate result of all the individuals' decisions. In each period each person will observe how much of the public good she/he is consuming and revise her/his prior estimate in line with this experience. Such a learning process according to McMillan can explain why individuals may not be inclined to free ride to a very great extent, ${ }^{6}$ and casts some doubt on the strong version of the free-rider hypothesis.

The question of whether there may be forces that run counter to the individual's tendency to be a free rider is addressed on a broader basis by various authors. ${ }^{7}$ Brubaker [1975]. for instance, has criticized the free-rider discussion for stressing and developing fully only those arguments that support and emphasize the importance of free riding. Possible motives for more collectively conscious behavior, on the other hand, are neglected. However, it may be, as recently emphasized by Margolis [1981], that individuals internalize their societies' standard of proper conduct so that, in effect, the individual's perception of the degree to which he/she is "behaving properly" or "sharing fairly" (a concept introduced by Margolis) enters as a separate argument in her/his utility functions. Similarly, Johansen [1977] and Richter [1978] have pointed out that economists treat free-rider behavior as being context-free, that they consider the tendency to free ride as a basic characteristic of human nature. ${ }^{8}$ It is quite possible that the individual may be guided by the advantages of a cooperative solution and willing to contribute toward it, provided that he/she receives some assurance that the other members of the community will also make an appropriate contribution toward helping to realize some specific level of provision of the public good in question. An individual may realize that the community has to make such a commitment or the public good will not be available for anyone. $\mathrm{He} / \mathrm{she}$ may fear that the other members of the community, for whatever reasons, will not commit

6. It may even be the case that the system reaches a Pareto optimum through such a trial and error process; see McMillan [1979b]. [1978].

7. See Brubaker [1975, 1979], Johansen [1977], Guttman [1978], and Richter

8. And in nearly all contributions to the subject the free rider is reduced to the role of a player in a noncooperative game; see, e.g.. Groves and Ledyard [1977[. 
enough of their resources to achieve it; but he/she may also, as Brubaker [1975, p. 152] has stated, "count on the community to commit itself to the purchase. Since he is counting on the rest of the community for the necessary tender, he may be willing to reciprocate by participating in a commitment to it."

These and some other arguments ${ }^{9}$ cast some doubt on the validity of the strong version of the free-rider hypothesis. It might be useful to examine an alternative, for example, that people may be disinclined to violate the norm that calls for honesty, and will thus reveal their true willingness-to-pay for a proposed amount of a public good. Both hypotheses can also be formulated more weakly. They are not mutually exclusive, but can provide a point of departure for a reconsideration of the free-rider problem.

The following section discusses an experiment that was carried out in order to get an idea of the importance of free riding in the real world. Theoretical reasoning alone clearly cannot settle this point. The experiment was conducted in such a way as to allow us (1) to examine whether the participants-depending on the different incentives offered by the experiment's three phases-behaved sy'stematically as free riders; and (2) to measure the extent to which free riding occurred.

\section{THE EXPERIMENT}

\section{A. Description of the Experiment}

In order to examine experimentally the extent to which people will behave as free riders, one has to create a situation characterized by a large group and a real public good. This requires that the cost of transactions within the group be very high; that there be nonrivalry in consumption of the good considered; that there be no possibility of exclusion of individuals from enjoyment of the public good; and that individuals recognize clearly the numerical imperceptibility of their decisions. ${ }^{10}$ Our procedure was similar to that used in a recent

9. These are discussed in greater detail by Brubaker $[1975$, p. 154]. In essence he argues the following: (i) in the case of public goods, the individual may positively value the knowledge that his "trading partners" also regard the contract as satisfactory; (ii) there may be interdependent preference functions; and (iii) the imminent breakdown of the provision of a public good (such as law and order) may present such a strong imperative for group action that it overwhelms the free-rider calculations.

10. Individual numerical imperceptibility, a concept introduced by Brubaker [1979], relates to whether a public-good situation is really created: The individually perceived group size must be large enough for the individual to see that he/she is not able to estimate the size of her/his latent demand relative to the aggregate, and thus the effect of his/her own offer on the total outcome. 
experiment by Brubaker [1979], but we modified the situation in three ways: (1) We wanted to eliminate the biases that can arise when only those people who are very interested and who may therefore be more inclined to cooperate, compose the experiment's sample. We thus included as actual participants all of the individuals whom we originally approached. This has not been done in any of the previous experiments, and their results may thus be open to question due to the unknown direction and extent of the biases. (2) Every participant was involved in every phase of our experiment. We did not break them up into separate groups, each of which was subjected to only one experimental situation, as has been done in nearly all other experiments. As we thus have a decision from each participant at every stage of the experiment, it is also possible to analyze which kinds of restrictions might have influenced the individual's decision. (3) The participants were deliberately not informed (and did not realize) that they were involved in an experiment in order to create a situation that would very closely approach the real world.

Our experiment was carried out with a class of forty-seven economics students at the University of Zurich. In order to create a relevant and realistic situation, a woman posing as the representative of a publishing company ${ }^{11}$ offered specimen copies of an economics textbook written by the class's professor (who, as the students were aware, was actually working on such a book). ${ }^{12}$ The 550 -page text was described as containing all of the material covered in the lecture courses dealing with the particular field, which would make it a most suitable basis for preparing for the upcoming final comprehensive (not end-of-semester) examinations. The students were told that the book would appear on the market in eighteen months, when it would be available at a student price of Swiss Francs (SFr.) 40 and a regular price of SFr. $55 .{ }^{13}$ The publisher, however, was said to be interested in getting comments and suggestions from the book's prospective audience that might help make it even more attractive and interesting. They were therefore making specimen copies available in four to six months, about a year ahead of publication date. Forty-four of the forty-seven students were to have their final examination before the textbook's publication in $1980 / 81$ and thus, had a strong incentive to

11. We would like to thank Haiga Jaick for playing the role of the representative. She did a great deal toward the creation of the feeling of an authentic situation.

12. The textbook's author was deliberately absent during the experiment in order to minimize this having an influence.

13. The price was calculated so as to leave no incentive for photocopying the textbook at the least expensive place that would normally be available to the students. 
try to obtain the book beforehand. Those receiving such copies were required to read it and make comments within three weeks of receiving it. The publisher would then return the books to the students, within three weeks at the most, for their private use.

The students, who according to a questionnaire they filled out afterwards did not realize that they were participating in an experiment, ${ }^{14}$ were told by the representative that the same offer of specimen copies was also being made to students in similar courses at two other universities, one of them in a foreign country. She claimed not to be able to say how large the total group was, but that it was large. It was thus possible to create a positive cost for transactions within the overall group, and it became difficult for the individual student at the University of Zurich to estimate the influence of her/his decision on the outcome.

Before moving into a public-good context, we tried in the first stage of the experiment to elicit participants' true willingness-to-pay for specimen copy. The students were given an opportunity to offer a written bid for the book, with the understanding that the ten highest offers from all three universities would be accepted. ${ }^{15}$ The bids from the other universities were said to be already known, so that the representative could determine immediately after the bidding which (if any) of the Zurich students would get one. After the bidding, and in our absence, the two highest bidders in the class were informed by the representative that they were among the ten highest in the overall group, and were excluded from the following phases of the experiment.

In the second phase of the experiment, a situation characterized by the usual collective-good properties was created. The students were told that the author of the textbook had suggested to the publishing company that it make an additional offer to the students. The idea was said to involve a greater number of students in making this preliminary examination of the text, and to compensate for the advantage that the economically better-off students had had with the first offer.

14. Only one of the participants felt throughout the whole experiment, and only two other students each in one of the various phases, that the situation might be arti. ficial. All three claimed that this had had no effect on the decisions they had made.

15. Following Vickrey [1971] and Smith [1967], it could be argued that in such a discriminative auction situation each accepted bid is filled at the bid price which provides an incentive to underreveal demand. But if all bids are filled at the highest rejected bid, each bidder has an incentive to bid true (in the case where each is bidding for a single item). Moreover, Brubaker [1979, Table 1, footnote a], using both types of auction rules, found that the difference between the two mean contributions was very small ( $\$ 32.28$ under discriminative as opposed to $\$ 33.99$ under the highest-rejected-bid rule). For this reason, and so as not to confuse the students with the use of a complicated bidding rule, we used the more common discriminative rule. 
The publishing company had thus agreed to send a specimen copy (still for commenting on) to each student if the participants at the three universities taken together were able to raise SFr. 4,200. If this amount was reached, each student would receive a copy regardless of the size of his/her individual contribution; if it were not reached, the company would not deliver any copies in addition to those promised to the ten highest bidders. In case the amount raised exceeded SFr. 4,200, the individual contributions would be reduced proportionally. After adding up the "Zurich" bids (again made anonymously in writing) and the pretended offers from the other two universities, the representative announced that the necessary amount unfortunately had not been reached, and thus only the highest bidders from phase 1 would be given copies. The publisher would, however, hold the offer open for a few days should the student still want to try to bring the money together.

We now came to the experiment's third phase. Here, in contrast to the possible exclusion of individuals by virtue of excluding the whole group (phase 2), there was no possibility of excluding anyone. After the representative had left, we informed the students that the author of the textbook had been concerned that the students would not be able to bring together the SFr. 4,200 . He thus had contacted a scientific foundation abroad, one of whose major goals was to support teaching and research. It was said that the foundation had agreed to cover the difference between the sum of the students' offers and the amount required by the publisher. Copies of the agreement were distributed to the students. This third offer clearly presented the strongest incentive to bid as low as possible (down to half a Swiss Franc: one had to bid at least this much to be included among those receiving the book). ${ }^{16}$

\section{B. The Results}

A comparison of the results for all three phases of the experiment for the forty-two participants remaining at the end ${ }^{17}$ shows that the three average offers are clearly positive (Table I). The $F$-test for the repeated measures analysis of variance ${ }^{18}$ rejects the hypothesis that

16. It was explicitly pointed out by us that the foundation would pay the difference even if only the minimal bid were offered.

17. Of the forty-seven students initially participating, we excluded those two who made the highest bids in the first round, and three others who did not fill out the questionnaire completely.

18. All computer calculations (repeated measures analysis of variance, as well as standardized regressions) were done with the BMDP (Bio-Medical Decision Program, Version 9, 1979) of UCLA. A full set of the results of the repeated measures analysis of variance can be obtained from the authors upon request. 
TABLE I

OFFERS OF THE ZURICH STUdENTS AT THE THREE STAGES OF THE EXPERIMENT, IN SFR

\begin{tabular}{|c|c|c|c|c|c|}
\hline & & & & \multicolumn{2}{|c|}{$\begin{array}{c}\text { Statistics of repeated } \\
\text { measures } \\
\text { analysis of variance }\end{array}$} \\
\hline & \multicolumn{3}{|c|}{ Stage of experiment } & $\hat{F}_{1}$ & $\hat{F}_{I I}$ \\
\hline & 1. & 2. & 3. & (d.f.) & (d.f.) \\
\hline Mean & 27.62 & 26.57 & 16.86 & 111.49 & 20.02 \\
\hline Standard & & & & & \\
\hline deviation & 4.99 & 4.83 & 3.98 & $(1: 40)$ & $(3 ; 123)$ \\
\hline
\end{tabular}

a. $F_{l}$ is an $F$-test of whether the expectation of the mean of the standardized sum of the three offers is zero in the repeated measures analysis of variance. $F_{I I}$ is an $F$-test of whether the expectation of the mean differences between all three offers is zero.

the expected means of the three stages are equal. Also the consecutive bids clearly decrease from one stage to the next and differ significantly. from each other ${ }^{19}$ showing that individuals react in a systematic and predictable way when the incentive structure is changed. These results are in accordance with those of recent experiments done by others ${ }^{20}$ and confirm the relevance of the free-rider hypothesis.

However, in accordance with all experiments done so far, ${ }^{21}$ the extent of the free riding also was rather modest.

Conditional on the possibility of sampling errors, and assuming that positive bids in the first stage represent true willingness-to-pay, it can be concluded that the forty-two students voluntarily offered on the average more than 61 percent of their estimated true willingness-to-pay (offer 3 divided by offer 1). Under the necessity of collectively offering the specified sum, about 96 percent of the estimated true willingness-to-pay was offered (offer 2 divided by offer 1): i.e., the possibility of individual exclusion through group exclusion resulted in revealing about 35 percent of the true willingness-to-pay more than when that possibility was ruled out.

In toto, these results are inconsistent with the free-rider view that dominates the traditional literature. In our experiment the partici-

19. The mean (standard deviation) of the difference between offers 1 and 2 is 1.05 (0.48); for offers 2 and 3 , it is 9.71 (1.78). The $F$-test of whether the expectation of the means of differences between two offers differs significantly shows values of 4.21 (offers 1 and 2) and 13.35 (offers 2 and 3 ). This indicates statistical significance at least at the 95 percent confidence level.

20. See Marwell and Ames [1979, 1980a, 1980b], Alfano and Marwell [1980], Guttman [1979], and Chamberlin [1978].

21. See the experiments mentioned above (compare footnote 201. Brubaker [1979]. and the classic investigations by Bohm [1972] and Sweeney [1973, 1974]. 
pants do not seem to be inclined to behave strategically to a very great extent even if there is an opportunity to do so. However, they also are not willing voluntarily to reveal their true willingness-to-pay.

\section{Evaluation of the Results}

Some objections can be raised with regard to our results and their interpretation, relating either to the relevance of the situation for the students at the individual stages, or to the fact that the whole experiment was done only once.

To start with the first set of possible objections:

1. It can be argued that the object being made available in the experiment, the specimen copy, was not relevant to the participants and that thus not too much confidence should be placed in the individual offers. The answers to the questionnaire, however, show that all of the students except two considered the specimen copy to be very relevant. In spite of this the experiment's individual phases were not treated the same. In the first round some of the students made offers clearly below their true willingness-to-pay; i.e., ten students offered zero Swiss Francs here but positive amounts of money in the next two rounds. ${ }^{22}$ One possible explanation for this result may be that some students may have tried to form coalitions: One student in a coalition is chosen to make a very high bid, and the remaining coalition partners, having no incentive to reveal their true willingness-to-pay, bid little or nothing. The possibility of forming coalitions cannot be excluded a priori and does indeed create a severe problem (but for all methods for revealing individual preferences for a public good). Opportunities for forming coalitions, however, were greatly limited by the representative's request for written bids (without discussion) and by the strong control exercised by us. ${ }^{23}$

Another possible explanation may be that these students thought that the phase-one offer was "unfair" because low-income students would a priori suffer a disadvantage. Low-income students might have thought that in an auction-like situation their offer would have no chance to be among the ten highest. They thus would not make a serious offer here, and what they would offer would then most probably be below their true willingness-to-pay. If income is really so important for the size of the offers in the first round, then it should be the

22. Their average offer was SFr. 21.55 in the second round, and SFr. 14.95 in the third round; both means differ significantly from zero at the 99 percent confidence level.

23. All forty-two students said in their questionnaires that they had been effectively prevented from forming such coalitions. 
dominant explanatory factor in a multiple regression trying to explain (in a statistical sense) the individual bids. To fulfill the ceteris paribus conditions, other independent variables have to be included, such as the subjective importance of the field "economic policy" in the forthcoming final examination, and the time restriction for reading and commenting on the specimen copy. The time restriction variable is a dummy variable with $0=3$ weeks sufficient for reading and commenting, and $1=3$ weeks not sufficient. The importance variable is the subjective estimated weight of the examination in this subject and varies from $1 / 3$ to $1 / 32$. The result for the OLS regression analysis for the first offer of the forty-two students is given below. ${ }^{24}$ The figures in parentheses below the parameter estimates indicate the $\hat{t}$-value; one asterisk indicates statistical significance at the 99 percent confidence level, using a two-tailed test. The figures in brackets are the $\hat{\beta}$-coefficients, showing the total influence of the variable:

\begin{tabular}{|c|c|}
\hline $\begin{array}{r}\text { Offer } 1=-5.93+0.030^{*} \\
(8.55) \\
{[0.712]} \\
-5.406 \\
(-1.30) \\
{[-0.304]} \\
+0.939^{*} \\
(4.41) \\
{[0.402]} \\
\bar{R}^{2}=0.77\end{array}$ & $\begin{array}{l}\text { time restriction for reading } \\
\text { and commenting } \\
\text { importance of the field } \\
\text { "economic policy" } \\
\qquad \hat{F} \text {-value }=43.24 ; \quad \text { d.f. }\end{array}$ \\
\hline
\end{tabular}

This result gives some evidence that income is the dominant factor influencing the size of the forty-two students' first offer. This is shown by the absolutely largest size of the $\hat{\beta}$-coefficient, and by this variable having the most significant impact. That means that if ceteris paribus conditions are fulfilled, the richer the students are, the higher the offers will be: The offer rises 3 Swiss Francs for every additional 100 Swiss Francs of income. The only other variable that has a significant influence is "importance of the field." From this we can conclude that part of the students may tend to make an offer below their true willingness-to-pay as they expect to lose in any case because of their low: income.

24. If we additionally include other independent variables such as time left until the final examination, or the possibility of photocopying the specimen copy at a lower than normally available price, the results does not improve. 
One way to explore the influence that the understated bids of lower income people may have on the average bid of the first round is to reestimate the above bidding function under exclusion of the ten zero bidders. The estimated coefficients can then be used to calculate the positive bids of these ten bidders, assuming that their demand behavior is not too deviant from that of the others. This was done and led to a somewhat higher average offer of SFr. 31.89 (instead of SFr. 27.62 ) in the first stage; but the general results did not change very much. ${ }^{25}$

2. Another objection may be that there was no real public-good situation for the participants in the experiment's second phase because of variation in perceptions of group size. Each participant could calculate that with a total number of participants of somewhat more than one hundred (105 participants) a normal student price of SFr. 40 would be sufficient to reach the fixed sum of SFr. 4,200 . It is, however, also possible for a student to imagine that there are still more participants, resulting in his/her making, ceteris paribus, a bid lower than SFr. 40. The mental state typical of a public-good situation (i.e., individual numerical imperceptibility) is then not created, and we can expect that the higher the estimate of the group size is, the lower the individual bid will be. To test this important objection, we have included the group size as individually estimated by the forty-two participants ${ }^{26}$ as an independent variable in the OLS regression equation explaining the offers at the second stage, with the expectation of a highly significant negative sign for this variable.

The result did show a negative sign for the group size variable, but the coefficient was not significant. ${ }^{27}$ It thus seems that we were able to create what was roughly a public-good situation. The question then arises, however, as to why the average bid was more than SFr. 26 in this stage of the experiment. We could conclude that there are strong forces running counter to the tendency to behave as a free rider. It might be that in this round the lower income students saw a real chance to get a specimen copy by acting cooperatively and that they

25. Instead of 61 percent, now 53 percent of the true willingness-to-pay is revealed (offer 3 divided by the modified first offer); under the restriction of collectively bringing together a fixed sum, 84 percent instead of 96 percent of the true willingness-to-pay is revealed.

26 . To get these figures, we explicitly asked in the questionnaire what the respondent estimated the group size to be and how this was calculated. Of the forty-two students, fourteen took the number of Zurich participants and simply multiplied it by three; twenty-eight students made separate "guesstimates" of the number of participants at the two other universities and added them to the Zurich students.

27. Explaining offer 2, the estimated coefficient for the group-size variable (measured in absolute units) is -0.006 , and the corresponding $\hat{t}$-statistic has a value of -0.60 . 
were thus willing to make an offer that came close to their true willingness-to-pay. ${ }^{28}$

3. Though the offers at the third stage of the experiment were, as expected, the lowest, they were still on the average more than 50 percent of the first bid. As argued by Brubaker [1975, p. 157] and Smith [1977, p. 1136], one reason for such a puzzling result may be that strategic behavior is so costly for the individual relative to expected benefit that a willingness-to-pay not far below the true one is revealed. However, in our situation there was no need to undertake a strategic calculation. Thus, our result indicates that there are forces running counter to extensive free riding - and we are as surprised as the reader by the strength of these forces. Ex post one can think of various possible explanations for our results, which indicates (as stated at the beginning) that the free-rider hypothesis provides only a partial description of the real world.

Possibly more important than these three objections may be that the results of only one experiment do not let us conclude what the individual's behavior would be like in a real public-good situation. The general results obtained by Brubaker (personal communication) and by Marwell and his colleagues ${ }^{29}$ in their repetitions of public-good experiments were not different from those they obtained the first time around. However, as these repetitions were done with different groups of participants and not with the same people, they show only that people do not behave strategically in an isolated and one-time experimental laboratory situation. If such an experiment (even slightly changed) is repeated with the same people, it cannot be excluded that the participants will learn and then begin to act more and more strategically, i.e., as utility maximizers in a strongly selfish way. Such kinds of learning effects have been found recently by Plott [1979] in a series of market experiments. However, public-good decisions occur in a context that is quite different from the market situation, and it is therefore open whether these results obtained for the market would hold generally. Results of a recent repetitive experiment by Smith $[1979 \mathrm{~b}, 1980]$ do not confirm the strong version of the free-rider hypothesis though considerable motives for this were created (the number of participants in the experiment was, however, quite small).

28. The effect we would expect is a decline in the importance of income for explaining the second (as compared with the first) offer. This was indeed the case: the estimated coefficient $(0.014: t=4.79 ; \beta=0.610)$ is smaller, but there is no significant difference between the two $\hat{\beta}$-coefficients.

29. Alfano and Marwell [1980], and Marwell and Ames [1980a]. 


\section{SUMMARY AND CONCLUSIONS}

The main result of our experimental study in public microeconomics is that there is only modest evidence for free riding as compared with the importance attributed to it in the literature. The individuals did systematically behave as free riders in line with the different incentives offered by the experiment's three stages, but the extent to which free riding occurred was not great. This conclusion is additionally supported by the fact that we used as subjects students in economics who had just been studying the free-rider problem. Our main result is also consistent with previous experiments and various case studies $^{30}$ that show that the free-rider problem cannot always be presumed to occur. It was not our aim to search out in detail the reasons that strong free riding does not occur, ${ }^{31}$ but we may conclude that the present dominance of the free-rider hypothesis rather indicates an incompleteness in standard public microeconomics than provides a description of the real world.

In our view, the next step should be to test explicitly the economic approach against alternative approaches to explaining individual behavior in a public-good situation. This would help economists to avoid the pitfall of believing that their traditional hypotheses form the only or most valid approach to explaining human behavior, though there is no question that they have a contribution to make. ${ }^{32}$

INSTITUT FÜR EMPIRISCHE W'IRTSCHAFTSFORSCHUNG DER UNIVERSITÄT ZURICH, SWITZERLAND

\section{REFERENCES}

Alfano, G., and G. Marwell, "Experiments on the Provision of Public Goods III: NonDivisibility and Free Riding in 'Real' Groups." Social Psychology Quarterly, XLIII (Sept. 1980), 300-09.

Arrow, K. J., "The Property Rights Doctrine and Demand Revelation under Incomplete Information," Discussion Paper No. 580, Harvard University, 1977.

Bohm, P., "Estimating the Demand for Public Goods: An Experiment," European Economic Review, III (June 1972), 111-30.

30. See e.g. the case study of Marsh [1976, 1978] on trade associations that provide a private as well as a public good for their members. Other case studies are given by Bolnick [1976] and Kikuchi, Dozina, and Hayami [1978] reporting on the financing of public goods (such as schools and health centers) by voluntary contributions, or by voluntary collective action (e.g., irrigation projects).

31. Our analysis should also not be interpreted as a test for the presence of rational self-interested behavior. Our main point was to give an indication as to the relevance of reconsidering the free-rider problem under a real world aspect.

32. For a nice example in the free-rider context showing that only economists (and not other people) think very much in economic terms, see the recent study by Marwell and Ames [1980b]. 
Bolnick, B. R., "Collective Goods Provision Through Community Development," Economic Development and Cultural Change, XXV (Oct. 1976), 137-50.

Brubaker, E., "Free Rider, Free Revelation, or Golden Rule," Journal of Lau and Economics, XVIII (April 1975), 147-61.

- "Thirteen Percent Golden Rule, Sixteen Percent Free Ride, and Seventy-One Percent Free Revelation? An Experimental Test of the Free-Rider Hypothesis," Discussion Paper, University of Wisconsin, 1979.

Chamberlin, J. R., "The Logic of Collective Action: Some Experimental Results," Behavioral Science, XXIII (Nov. 1978), 441-45.

Clarke, E. H., "Multipart Pricing of Public Goods," Public Choice, XI (Fall 1971), 19-33.

- Demand Revelation and the Provision of Public Goods (Washington, D.C.: Woodrow Wilson Center, 1978).

Green, J. R., and J.-J. Laffont, Incentives in Public Decision-Making (Amsterdam: North-Holland, 1978).

Groves, T., "Incentives in Teams," Econometrica, XLI (July 1973), 617-31.

, and J. D. Ledyard, "Optimal Allocation of Public Goods: A Solution to the "Free Rider' Problem," Econometrica, XLV (May 1977), 783-809.

Guttman, J. M., "Understanding Collective Action: Matching Behavior," American Economic Review Papers and Proceedings, LXVIII (May 1978), 251-55.

- "Matching Behavior and Collective Action: Theory and Experiments," Discussion Paper, Hebrew University, 1979.

Hume, D., Treatise on Human Nature (London: Oxford University Press, 1975 [1740: lst ed.]).

Johansen, L., "The Theory of Public Goods: Misplaced Emphasis?" Journal of Public Economics, VII (Feb. 1977), 147-52.

Kikuchi, M., G. Dozina, and Y. Hayami, "Economics of Community Work Programs: A Communal Irrigation Project in the Philippines," Economic Development and Cultural Change, XXVI (Jan. 1978), 211-25.

Margolis, H. M., "A New Model of Rational Choice," Ethics (Jan. 1981), 26579.

Marsh, D., "On Joining Interest Groups: An Empirical Consideration of the Work of Mancur Olson, Jr.," British Journal of Political Science, VI (July 1976), 25771.

, "More on Joining Interest Groups," British Journal of Political Science, VIII (July 1978), 380-84.

Marwell, G., and R. E. Ames, "Experiments on the Provision of Public Goods I: Resources, Interest, Group Size, and the Free Rider Problem," American Journal of Sociology, LXXXIV (May 1979), 1335-60.

__ Stakes, Experience and the Free Rider Problem," American Journal of Sociology, LXXXV (Jan. 1980a), 926-37.

, and _ - "Economists Free Ride, Does Anyone Else? Experiments on the Provision of Public Goods, IV," Discussion Paper, University of Wisconsin, $1980 \mathrm{~b}$.

McMillan, J., "Individual Incentives in the Supply of Public Inputs," Journal of Public Economics, XII (Aug. 1979a), 87-98.

, "Public Goods Equilibrium," Discussion Paper, University of Western Ontario, $1979 \mathrm{~b}$.

Mueller, D. C., "A Comparison of Some New and Old Voting Procedures," Discussion Paper, University of Maryland, 1979.

Musgrave, R. A., The Theory' of Public Finance (New York: McGraw-Hill, 1959).

Olson, M., The Logic of Collective Action (Cambridge, MA: Harvard University Press, $1965)$.

Plott, C. R., "The Application of Laboratory Experimental Methods to Public Choice," in C. S. Russell, ed., Collective Decision Making: Applications from Public Choice Theory (Washington, D. C.: Resources for the Future, 1979), pp. 131-71.

Richter, W., "Eine Charakterisierung des Trittbrettfahrerverhaltens," in E. Helmstaedter, ed., Neuere Entwicklungen in den Wirtschaftswissenschaften (Berlin: Duncker \& Humblot, 1978), pp. 101-14.

Roberts, D. J., "The Incentives for Correct Revelation of Preferences and the Number of Consumers," Journal of Public Economics, VI (Nov. 1976), 359-74. 
Samuelson, P. A., "The Pure Theory of Public Expenditure," Review of Economics and Statistics, XXXVI (Nov. 1954), 387-89.

Satterthwaite, M. A., "Strategy-Proofness and Arrow's Conditions: Existence and Correspondence Theorems for Voting Procedures and Social Welfare Functions," Journal of Economic Theory, X (April 1975), 187-217.

Scherr, B. A., and E. M. Babb, "Pricing of Public Goods: An Experiment with Two Proposed Pricing Systems," Public Choice, XXIII (Fall 1975), 35-48.

Smith, V. L., "Experimental Studies of Discrimination Versus Competition in Sealed-Bid Auction Markets," Journal of Business, XL (Jan. 1967), 54-84.

—_ "The Principle of Unanimity and Voluntary Consent in Social Choice," Journal of Political Economy, LXXXV (Dec. 1977), 1125-39.

- "Incentive Compatible Experimental Processes for the Provision of Public Goods," in V. L. Smith, ed., Research in Experimental Economics, Vol. 1 (Greenwich, CT: JAI Press, 1979a), pp. 59-168.

- "An Experimental Comparison of Three Public Good Decision Mechanisms," Scandinavian Journal of Economics, LXXXI (1979b), 189-215.

- "Experiments with a Decentralized Mechanism for Public Good Decisions," American Economic Review, LXX (Sept. 1980), 584-99.

Stigler, G. J., "Free Riders and Collective Action: An Appendix to Theories of Economic Regulation," Bell Journal of Economics and Management Science, V (Autumn 1974), 359-65.

Sweeney, J. W., "An Experimental Investigation of the Free-Rider Problem," Social Science Research, II (June 1973), 277-92.

- "Altruism, the Free Rider Problem and Group Size," Theory and Decision. IV (Feb. 1974), 259-75.

Tideman, T. N., "The Efficient Provision of Public Goods," in S. J. Mushkin, ed., Public Prices for Public Products (Washington, D. C.: Urban Institute, 1972), pp. 111-23.

— , and G. Tullock, "A New and Superior Process for Making Social Choices," Journal of Political Economy, LXXXIV (Dec. 1976), 1145-59.

Vickrey, W., "Counterspeculation, Auctions, and Competitive Sealed Tenders," Journal of Finance, XVI (May 1961), 8-37. 